IJ§ER

ISSN: 2149-5939
International Journal of Social Sciences and Education Research

Online, http://dergipark.gov.tr/ijsser

Volume: 3(2), 2017

\title{
Teaching language through the use of literature in ESL classes with the implementation of CEFR
}

\author{
Sümeyra Bağatur ${ }^{1}$
}

Received Date: $01 / 09$ / 2016

Accepted Date: 15 / $01 / 2017$

\begin{abstract}
For language teaching many resources have been used as a vehicle to teach the language more efficiently in the course of time. It is, however, widely accepted that literature has proved to the the best and the most beneficial resource in language teaching. It is of great value in this sense. This paper will first present some ideas about the use of literature in language teaching, then, I will explain why we use literature, and how we should choose literary texts in our language classes. In the following part, I will present the second part of the paper, which is composed of the literary genres like novel, short story, drama and poetry. And in the closing part, I will give an interpretation of Common European Framework of References (CEFR) and how the use of literature can be implemented into CEFR in language teaching.
\end{abstract}

Keywords: English language teaching, literature in language teaching, Common European Framework of References (CEFR)

\section{Introduction}

For language teaching many resources has been used as a vehicle to teach the language more efficiently in the course of time. It is, however, widely accepted that literature has proved to be one of the most beneficial resources in language teaching. It is of great value in this sense. Therefore, in this study I will first present some ideas about the use of literature in language teaching, then, I will explain why we use literature, and how we should choose literary texts in our language classes. And then the literary genres will be given. And in the closing part, I will give an interpretation of Common European Framework of References (CEFR) and how the use of literature can be implemented into CEFR in language teaching.

\section{Arguments against the use of literature in language teaching}

Literature represents the ultimate level of the language in terms of vocabulary, structures, expressions, variety of usages and the richness of sayings. Such a resource clearly becomes indispensable for language teaching. In this sense, as language teachers we should make most of literature while teaching the language.

However, in the course of language teaching, there has been some arguments against using literature language teaching for a long time. As McKay (1996) suggests some people say that "as our goal is to teach the grammar of the language, literature, due to its structural complexity and its unique use of language, does little to contribute to this goal." On the other hand, we know for sure that learners cannot go beyond their present level without being exposed to a level just beyond their level. The theory behind this idea is the zone of proximal, which proposes teaching

\footnotetext{
${ }^{1}$ Hacettepe University, Department of English Language Teaching, Ankara-TURKEY, sumeyra.bagatur@gmail.com 
Bağatur, S. (2017). Teaching language through the use of literature in ESL classes with the implementation of CEFR. International Journal of Social Sciences and Education Research, 3(2), 531-539.

students at an upper level from their present level, otherwise they cannot improve and stay at the same level of proficiency.

Another argument against using literature in language teaching is that "the study of literature will contribute nothing to helping our students meet their academic and/or occupational goals" (McKay, 1996). People in favour of such a thought seem to think a bit narrow in that literature may not make a learner build something solid in their academic lives; rather it should be seen as a long term process in which learners benefit from even sometimes without being aware of it. In this sense, we should be careful in that literature does not blossom the fruit overnight, it requires some time for maturation in the learning and academic process of the students to merit from.

The last argument McKay (1996) presents us is that "literature often reflects a particular cultural perspective; thus on a conceptual level, it may be quite difficult for students." It is quite weird that many people put forward such an argument because our aim is not to teach the language in isolation, in contrast, it is to teach it in its own cultural context and values. We cannot separate literature from its components like social, cultural, traditional perspectives.

\subsection{The use or the usage of the language}

Before going into the details of the language and literature, maybe we should first be able to differentiate between the "use" and the "usage" to make clear understanding of the issue at hand. "Usage involves a knowledge of linguistic rules, whereas use entails knowing how to use these rules for effective communication" (Widdowson, 1978). As it is clear from the definition, usage enables us to make sentences, to place the words appropriately in the sentences, and to apply grammatical rules. However, use of the language covers all we do with what we know of the language. It contains all aspects of the language. Without an effective use of the language the usage cannot be of any significance. So, what we can ask in this case is "can a literary text contribute to a knowledge of either one?" (Widdowson, 1978). As literature, both feeds the learner with the use and usage of the language, we can very well say that literature inherently helps the learner improve both of them at the same time. For instance, vocabulary expansion is dealt with by attention to word forms and common expressions, the structures are dealt with sentences, dialogues, descriptions, etc., the rules of the grammar are learned inductively by the students while they are studying a literary text. Many scholars accept with ease that literature helps the learners improve their language level more than it has been realized in the academic field.

\subsection{Why to use literature}

We have seen that literature is the resource of language, and we have some reasons to use this rich resource in our classes. Akyel \& Yalçın (1990) name some of these reasons as in the followings: "To broaden students' horizons by giving them a knowledge of the classics of literature." We know that learners have individual differences and their interests may differ from one another. Literature presents numerous worlds for them to step into; and in this way, each learner can enjoy to find something attractive to her interests. Another reason to use literature can be that it can be used "to improve students' general cultural awareness." Literature encompasses all the cultural context and values of that language; therefore, the more learners read the literature of that language, the more they get familiar with the culture of the target language. And in the teaching process, one of our main goals is to gain them some cultural awareness of the target language. 
Bağatur, S. (2017). Teaching language through the use of literature in ESL classes with the implementation of CEFR. International Journal of Social Sciences and Education Research, 3(2), 531-539.

Evident from the above suggestion, literature becomes one of the vital parts of our teaching language in this sense.

Literature can also be used "to stimulate students" creative and literary imagination and to develop their appreciation of literature." No world has been so interesting than the ones that literature has created. If we look at for instance Lord of The Rings, we can easily grasp what great help literature does to imagination. Creativity is one of the invaluable things in education; we want our students to be creative and original in their schooling process and to carry that merit of theirs with themselves to their life outside school. As teachers, we feel for sure that once creativity emerges, it continues for a long time in one's life. So, literature opens and widens the perspectives and minds of the learners with its fantastic and imaginative worlds special to itself.

One last reason to use literature in our language classes is "to introduce students to masterpieces in British and American literature as an educative experience, and to add students' knowledge of the world at large." Being in touch with the world of the target language through the literature provides the learners with a wide knowledge of the world with which they are not so familiar with. Through literature, they move from their locale and see the one unfamiliar to them. This again gains them a kind of perspective from which they can have a look at themselves and their own worlds. Therefore, literature also proves to be the help for the learners to discover themselves with the world of the others, and be able to have a different viewpoint from that world.

\subsection{Literature and its relation to skills}

In language teaching four basic skills are of great importance for us to improve in our students. As Povey (1972) states "literature will increase all language skills because literature will extend linguistic knowledge by giving evidence of extensive and subtle vocabulary usage, and complex and exact syntax." A reading text can be read by the teacher to the class; then the students can read it loud, and it can be acted out in the class, and then the teacher can ask the students to write an extra page to the end of the text. Through such a process, we may make use of literature for the linguistic development of our students in terms of their language skills. We should always keep in mind that teacher may use literature for the improvement of all basic language skills as long as she wants to, and she will see that literature proves to be such a great resource for us in language teaching.

\subsection{Interaction to literature}

Literature is a subtle way to discover ourselves in it; but to do it, we first have to understand the language and meanings lying beneath the surface. In this sense, Widdowson (1979) and Johnson (1981) suggest that "reading necessitates the ability to interact with a text by decoding the language and comprehending the concepts presented." We have to understand what the text says to us, and we need to catch the meaning and philosophy behind. In all this process, we are going through a direct interaction with the text itself. And everyone may get a different idea and message from the same text. Therefore, we need to teach our students that literature can be of good use for them if they take it as something they can communicate and interact with. In this way, students will open their minds to the boundless horizons of the worlds some of which may have never occurred to the students before. Through such an interaction, students will feel that they have discovered something special to them. Also, interaction presupposes the fact that a reader is willing to interact with a particular text. And we are always trying to have motivated students, and 
Bağatur, S. (2017). Teaching language through the use of literature in ESL classes with the implementation of CEFR. International Journal of Social Sciences and Education Research, 3(2), 531-539.

here, motivational factors involved in reading become critical as the students will get more and more motivated in their learning process.

For Collie and Slater (1990) literature provides us with valuable authentic material. We do not have to go in search of other materials prepared for language teaching. As we have all authentic materials, we are more into the target language and culture in this sense. Therefore, we can feel safer and more content that our students are in a closer interaction with the target language. In this regard, literature also presents us the cultural enrichment of the target language. All the bits and pieces in a literary text gives away all the details about the target culture. We can never disregard such a resource in this sense, and as language teachers should make most of literature in our classes.

Literature provides us with a variety of linguistic expressions. The language enrichment is another merit we benefit from in our language classes. The learners get imposed to a variety of structures and usages during studying a literary text. Sometimes they are not aware that they are learning some structures and sometimes when they use some different structures they cannot tell how or when they have learnt them. Therefore, students should always be in good touch with the literary texts even after the schooling term, they should be in close control by the teachers and the parents.

Although we presuppose literature be studied at school with language classes, it is a fact that studying literature is an individual activity. Readers of literature can enjoy it however they like, similarly, they can get whatever they want from the literary texts. It has no clearcut facts for limiting the messages, the symbols, the identifications, the morales in a text. Therefore, there should be a kind of personal involvement in the process of reading a literary text.

\subsection{Aims in the use of literature in language teaching}

Carter and Long (1991) put forward three main models for the aims of the use of literature in language teaching:

The cultural model is what we are presented from the actual target language. Language learners through getting more and more familiar with cultural values and merits of the target language, feel closer to that language and culture. If a language is taught without any cultural items of the target language, it is almost impossible for the learner to grow a certain close feeling towards that language. And we know that nothing can be learnt well unless there is a certain degree of love in it. Therefore, what is highly suggested is that we need to include the cultural items of the target culture into our classes. Through such an implementation, learners will familiarise with the target culture and start developing a particular sympathy towards the target language.

The second model Carter and Long (1991) propose is the language model. Literature includes a limitless use of the language. No other resource can be so rich in this sense. Therefore, we need to take this fact into consideration if we want to raise fully successful and self-confident language students.

The last model is the personal growth model, in which learners go through a process of personal growth while studying literary text in more and more detail because the more they dive into those texts, the more they will identify themselves with. They will take those texts as an embodiment of their personal discovery and improvement in this sense. Therefore, literature will not 
Bağatur, S. (2017). Teaching language through the use of literature in ESL classes with the implementation of CEFR. International Journal of Social Sciences and Education Research, 3(2), 531-539.

only serve for their academic success but also to their gaining a new view towards life and themselves which will make them full individuals in the society.

\subsection{Literature as a potent resource}

For Maley (1989) literature is a potent resource because of its:

Universality: Literature is universal in that it analyses human being in close view. Therefore, it can never be outfashioned or out of date.

Non-triviality: Even small details prove to mean something important in a literary text and sometimes stand for some symbols in this sense.

Personal relevance: Everyone can find something familiar with her own life in literature. A king and a janitor staff can identify themselves with Raskolnikov in Crime and Punishment; so it is not hard to say that literature brings all the human beings together without any difficulty.

Variety: Literature enjoys variety in many aspects, like variety in language use, variety in creativity, variety in the items used in the text, etc.

Interest: As the main focus is the human being, all the readers can find it interesting for their own sake.

Economy and suggestive power: Literature says more than it reads. King Lear is forty pages, however, the ideas and philosophies developed over that masterpiece has been in volumes. Therefore, literature is concise and at the same time suggestive in itself.

Ambiguity: Literature enjoys carrying the ambiguity as one of its characteristics. The curiosity raised over ambiguity creates the attraction and the interest in the work.

\subsection{How to choose a literary text}

As language teachers, we should be careful while selecting a suitable literary text for our language class. As McKay (1996) puts "selecting the text is only the first step. An equally important issue is how to deal with such texts in the classroom." We need to show great care to the students' needs, their interests, their cultural background, and their language level.

Brumfit (1985a) suggests that we need to take some basic points into consideration like linguistic level, cultural level, length, pedagogical role, genre representation, and classic status of a literary text.

Brumfit (1996b) also asks "is literature taught or caught?" suggesting that what we try to teach our students may have already been "caught" by our students. He also pinpoints that "there is a misunderstanding of the nature of teaching any complex subject. None of us teaches anything worthwhile directly to students: we simply create the conditions for successful learning" (1996b). Therefore, we need to drive them towards being more creative and more autonomous. He also says that "only in a trivial sense, but over a long period we expect to see an interest in literature. Because we do not expect them to replicate our responses in detail, but to develop their own, this is the thing that can be caught in a reasonably knowledgeable adult reader" (1996b). He advices us to leave our students free in their thinking and imaginative stage of processing, because only in this way can they be fully freethinking and self-directed individuals in their lives. Remembering that a lifelong learning is the ideal aim of a teacher, we should keep it in mind that our students 
Bağatur, S. (2017). Teaching language through the use of literature in ESL classes with the implementation of CEFR. International Journal of Social Sciences and Education Research, 3(2), 531-539.

will benefit from this kind of teaching especially in their life after school years. Literature is a tool to take the learners to their ideal self, so "responding to literature is not a matter of basic understanding of the language of the text. It is the significance of the text that is important to the good reader, not its ability to be translated exactly" (Brumfit, 1996a).

We should also highlight that while studying literary works of the target language, the students also get familiar with the other nations. Especially if we provide them with the literature of the non-English origin, they can gain a wider perspective towards the target language. For instance, as Kachru (1983) exemlifies "Chinua Achabe, Amos Tututola, Raja Rao, Slamna Rushdie, Ngugi wa Thiong'o, Doris Pilkington Garimara (from Nigeria and India, Australia) raise the issue of creative writing by non-western bilingual users of the issue of English in typical non-western settings where English is primarily used as an institutionalized second language." Such writers write in English language but with a non-English perspective; so it will be of great value for making our students aware of different viewpoints in the world. In this way, they will become familiar with the world issues, realities, thoughts and beliefs existing in the world.

\section{Literary genres}

Literature has some genres like novels, short stories, plays and poems. In our language classes we may make use of them very sufficiently if we organize and prepare our students well enough for the class.

\subsection{Novel}

Novel is the genre which allows for extensive reading, so it facilitates general proficiency of the students. So, we can make use of novels in such ways like reading skills, vocabulary development, speaking skills, writing skills, grammar, integrated language skills.

\subsection{Short story}

For Murdoch (2002) short stories can, if selected and exploited appropriately, provide quality text content which will greatly enhance ELT courses for learners at intermediate levels of proficiency.

There are some advantages of short stories like: they are not long to spend too much time on. The setting and plot can be interesting and vivid for the students. The students may enjoy the dialogues, so following the course of communication. Short stories make the students' reading task easier due to being simple and short when compared with the other literary genres. They enlarge the advanced level readers' worldviews about different cultures and different group of people. Short stories provide more creative, encrypt, challenging texts that require personal exploration supported with prior knowledge for advanced level readers. They motivate learners to read due to being an authentic material. They offer a world of wonders and a world of mystery. They give students the chance to use their creativity and promote critical thinking skills. They facilitate teaching about a foreign culture and make students feel themselves comfortable and free. They help students coming from various backgrounds to communicate with each other because of its universal language and to go beyond the surface meaning and dive into underlying meanings. They also act as a perfect vehicle to help students understand the positions of themselves as well as the others by transferring these gained knowledge to their own world. 
Bağatur, S. (2017). Teaching language through the use of literature in ESL classes with the implementation of CEFR. International Journal of Social Sciences and Education Research, 3(2), 531-539.

\subsection{Drama}

Different from the other genres, drama has a multi-sensory approach. It includes both bodily and linguistically features in it. So it allows learners to explore linguistic and conceptual aspects without concentrating on the mechanics of language. To have a real communication, we need ideas, emotions, feelings and appropriateness and adaptability in language. The learners are quite free and relax in drama acts in the class as they realize that whatever they do or say is not used against her, but as she has a new identity, all the faults will be of that person she is performing.

Communication is important in drama classes. Unlike traditional classes there is a high use of the language for expressing the feelings and the actions of the students. Besides that, there is a constant interaction and dialogue taking place between the students and, teacher and students which helps all the class members be alert and interested in the class. So, the use of the language becomes a must to enable the communication in a drama class. In this way, both language and the creative thinking of the students improve at the same time.

\subsubsection{Benefits of drama in language classes}

Sarıçoban and Küçükoğlu (2013) highlight the benefits of plays in language classes in that students can explore the issues within the story before meeting the text. They can enact scenes in the original text. They can take the roles of characters or voices from the text and be questioned about motives and intentions, and use space and objects in a variety of realist and symbolist ways to represent meanings in the text, to physically represent the physical or cultural distance between characters. They can create missing scenes or moments that are suggested but not fleshed out in the original text and explore how to use gesture to convey sub-text; how inner speech can be visibly played for instance. Students script or improvise alternative scenes or endings and extend the story back in time or forward into an imagined future. They can add or expand minor characters and their lives and involvement. They can demonstrate to each other that there can be a variety of possibilities when it comes to the interpretation and representation of meanings.

For Vygotsky (1987) students feel more self-conscious and more empowered to express themselves through the multiple voices of the differing characters and learning becomes more colourful, interesting and more learner-centered, thus, a more meaningful, realistic, long-lasting and effective learning takes place in a drama class.

\subsection{Poetry}

For Saraç (2003) poetry provides readers with a different viewpoint towards language use by going beyond the known usages and rules of grammar, syntax and vocabulary. It also triggers unmotivated readers owing to being so open to explorations and different interpretations and evokes feelings and thoughts in heart and in mind. It makes students familiar with figures of speech (i.e. Simile, metaphor, irony, personification, imagery) due to their being a part of daily language use (Saraç, 2003).

For Holmes and Moulton (2001), writing simple and short poems enable students to:

Play with words and see what fits because the burden of discovering a proper format for a poem is removed

Create a polished piece of writing in a relatively short period, thereby experiencing instant gratification 
Bağatur, S. (2017). Teaching language through the use of literature in ESL classes with the implementation of CEFR. International Journal of Social Sciences and Education Research, 3(2), 531-539.

Rehearse correct spelling

Use familiar vocabulary

Discover new vocabulary while using the dictionary or thesaurus to find words that serve their ideas

Practise specific language structures such as phrases, word order and verb tense

Develop confidence in their ability to share ideas in writing

Nurture creativity by giving their imaginations free reign

Cultivate logical and sequential thinking skills through storytelling

Refine summarizing skills.

\section{Use of literature in accordance with the Common European Framework of Reference}

Common European Framework of Reference (CEFR) bases an action oriented approach on its center. Action oriented approach means that learning does not remain in the classroom environment, but it is carried to outside class, to real life situations. Therefore, we can say that the use of literature may not only mean to enwiden the minds and the use of the language of the students but it also helps them to carry this kind of critical thinking outside the classroom environment.

Also regarding the linguistic levels of the learners, we can say that a careful selection of the literary works can be of great help to be in good accordance with CEFR. The linguistic level of the learners should be a criteria for choosing an appropriate text for them. The abridged versions of the texts, the simplified editions of them can be used in the language classes.

CEFR also focuses on the cultural aspect of the language. It suggests that languages cannot be handled and taught separatedly from their cultures. Therefore, literature can be highly invaluable in teaching languages in this sense as literary texts contain many items from culture, tradition and lifestyles of the target language.

Also CEFR pinpoints the idea of individual differences as it emphasizes the humanistic view in education. In this sense, literary texts may help students to get what they infer from the text, not a clearcut fact from it. Every student thereby may enjoy the freedom of getting their own judgements or ideas about it at the same time.

The idea of cultural awareness is thus emphasized in the scope of CEFR. Teachers are advised to provide the learners with materials including cultural and traditional values in them. In this way, learners gain a familiarity with the target language, and get to feel closer to the language and the native speakers of the target language. This is highly significant in that some learners develop a kind of negative attitude towards the target language which hinders her back from learning the language. Thus, making learners realize and familiarize them with the target culture should be on the focus of the teachers and educators in language teaching.

\section{Conclusion}

In this paper, I have attempted to show the basic arguments developed against the use of literature in language teaching, and then mentioned the benefits of the literature in language teaching. I also gave some suggestions for the main points while choosing a literary text. After these, I 
Bağatur, S. (2017). Teaching language through the use of literature in ESL classes with the implementation of CEFR. International Journal of Social Sciences and Education Research, 3(2), 531-539.

presented the literary genres, how they can be used in a language class and stated some of the benefits of these literary genres for teaching language. And in the last part, I made an interpretation of the use of literature in relation to the CEFR covering the main points it focuses like cultural values, action oriented approach and the linguistic levels of the learners.

\section{References}

Akyel, A. \& Yalçın, E. (1990). Literature in the EFL class: A study of goal achievement incongruence. ELT Journal 44(3), 174-180.

Brumfit,C.J. (1996a). Reading skills and the study of literature in a foreign language. Literature and language teaching. C.J. Brumfit \& R.A. Carter. Hong Kong: Oxford University Press. 184-190.

Brumfit,C.J. (1996b). Literature and education. Literature and language teaching. C.J. Brumfit \& R.A. Carter. Hong Kong: Oxford University Press. 22-34.

Brumfit,C.J. (1985). Language and literature teaching from practice to principle. Pergamon Press. Ltd. England: Oxford.

Carter, R \& Long, M.N. (1991). Teaching literature. England: Longman Group UK Limited.169-181.

Collie, Joanne \& Slater, Stephen. (2003). Literature in the language classroom: A resource book of ideas and activities. Cambridge Handbooks for Language Teachers Series. Ed. Penny Ur.

Holmes, V.L. \& Moulton, M.R. (2001).Writing simple poems. Cambridge: CUP.

Johnson, P. (1981). Effects on reading comprehension of language complexity and cultural background of a text. TESOL Quarterly. 15(2).

Kachru, B. (1983). The biligual's creativity: Discoursal and stylistic strategies in contact literatures in English. Studies in the Linguistic Sciences. 13(2). 38-55.

Maley, Alan. (1989). Down from the pedestal: Literature as resource. Literature and the şearner: Methodological approaches. Cambridge: Modern English Publications.

McKay, Sandra. (1996). Literature in the ESL classroom. Literature in the language classroom: $A \quad r e-$ source book of ideas and activities. C.J. Brumfit \& R.A. Carter. Cambridge Handbooks for Language Teachers Series. Ed. Penny Ur. 191-198.

Povey, J. (1972). Literature in TESL programs: The language and the culture. H. Allen \& R. Campbell (ed.) Teaching English as a second language. New York: Mc. Graw Hill.

Saraç, S. (2003). A suggested syllabus for the teaching of poetry course in ELT departments of Turkey. Unpublished M.A. Thesis. Ankara: Hacettepe University.

Sarıçoban, Arif \& Küçükoğlu, Hülya. (2013). Teaching English through literature. Ankara.

Vygotsky, L.S. (1987). Thinking and speech. Eds. Rieber and Carton. The collected works of Vygotsky. New York: Plenum.

Widdowson, H.G. (1979). Explorations in applied linguistics. Oxford: Oxford University Press.

Widdowson, H.G. (1978). Teaching language as communication. Oxford: Oxford University Press 